06,17

\title{
Электрические параметры материалов на основе модифицированных эндоэдральных металлофуллеренов
}

\author{
(ㄷ Г.Н. Чурилов ${ }^{1,2}$, А.И. Дудник ${ }^{1,2}$, Н.А. Дрокин ${ }^{1}$, Н.Г. Внукова ${ }^{1,2}$, \\ B.С. Бондарев ${ }^{1,2}$, В.И. Елесина ${ }^{1,2}$ \\ ${ }^{1}$ Институт фозики им. Л.В. Киренского ФИЦ КНЦ СО РАН, \\ Красноярск, Россия ${ }^{2}$ Сибирский фредеральный университет, \\ Красноярск, Россия \\ E-mail: churilov@iph.krasn.ru
}

(Поступила в Редакцию 23 октября 2018 г.)

\begin{abstract}
Представлены результаты исследования пленки на основе гидроксилированных эндоэдральных металлофуллеренов (ЭМФ) с $Y$. Показано, что полученная пленка является ионным проводником и может проявлять свойства сегнетоэлектрика.
\end{abstract}

DOI: $10.21883 /$ FTT.2019.03.47243.292

Молекулы ЭМФ имеют некоторые особенности в структуре расположения атомов. Как и в обычных фуллеренах, атомы углерода располагаются на квазисферической поверхности и имеют обобщенную $\pi$-систему электронов. При этом имеется атом-гость, который находится внутри каркаса и располагается вблизи поверхности. Обычно два или три валентных электрона этого атома (или молекулы) также принадлежат обобщенной $\pi$-системе.

Вещества на основе ЭМФ интересны как с фундаментальной, так и с прикладной точки зрения [1-4]. В литературе обширно представлены результаты исследований возможностей применения модифицированных фуллеренов, например, в качестве твердого электролита, контрастного агента для магнитно-резонансной томографии или прекурсоров для получения препаратов с противовирусной и противораковой направленностью [5-7].

В отличие от молекул фуллеренов с пустым каркасом, электрические свойства модифицированных ЭМФ недостаточно хорошо исследованы $[8,9]$. Это связано со сложностью их получения и выделения в достаточных для проведения экспериментов количествах. Нами разработана методика получения углеродного конденсата (УК) в ВЧ дуговом разряде с высоким содержанием ЭМФ с $Y[10,11]$. Применяя эту методику и современные методы выделения ЭМФ, мы получили композит эндоэдральных металлофуллеренов $Y @ \mathrm{C}_{82}, Y_{2} @ \mathrm{C}_{82}$ с небольшими примесями $Y_{2} \mathrm{C}_{2} @ \mathrm{C}_{82}$ и высших фуллеренов в достаточных для изготовления пленки количествах. Обогащение ЭМФ осуществлялось по методике, основанной на применении кислоты Льюиса $\mathrm{TiCl}_{4}$ [12]. Полученный образец фуллереновой смеси был аттестован методом масс-спектрометрии (MALDI-TOF Bruker BIFLEX TM III), рис. 1.

Полученные ЭМФ были модифицированы методом кипячения в концентрированной кислоте HNO3 [13]. В результате был получен водный раствор гидроксилированных ЭМФ с $Y$. Раствор прокапывался на измери- тельный датчик, выполненный в виде плоской встречноштыревой металлизированной структуры на подложке из поликора. В процессе прокапывания раствор сушился при температуре $23^{\circ} \mathrm{C}$ до образования пленки.

Электрофизические характеристики ЭМФ определялись методом импедансной спектроскопии на анализаторе импеданса Agilent Technologies E5061B в диапазоне частот $1 \mathrm{~Hz}-100 \mathrm{MHz}$ и на WK4042 в диапазоне частот 0.1-1 MHz. На измерительный датчик подавалось напряжение $0.25 \mathrm{~V}$.

Методом рентгеновской фотоэлектронной спектроскопии (РФЭС) был определен элементный состав пленки: углерод - 75.09 at.\%, кислород - 24.78 at.\%, иттрий - 0.13 at.\%. Анализ РФЭС линии C $1 s$ показал, что в состав пленки входят гидроксилированные ЭМФ и высшие фуллерены.

Измерения частотной зависимости модуля импеданса $|Z(f)|$ и фазы $\varphi(f)$ проводились при

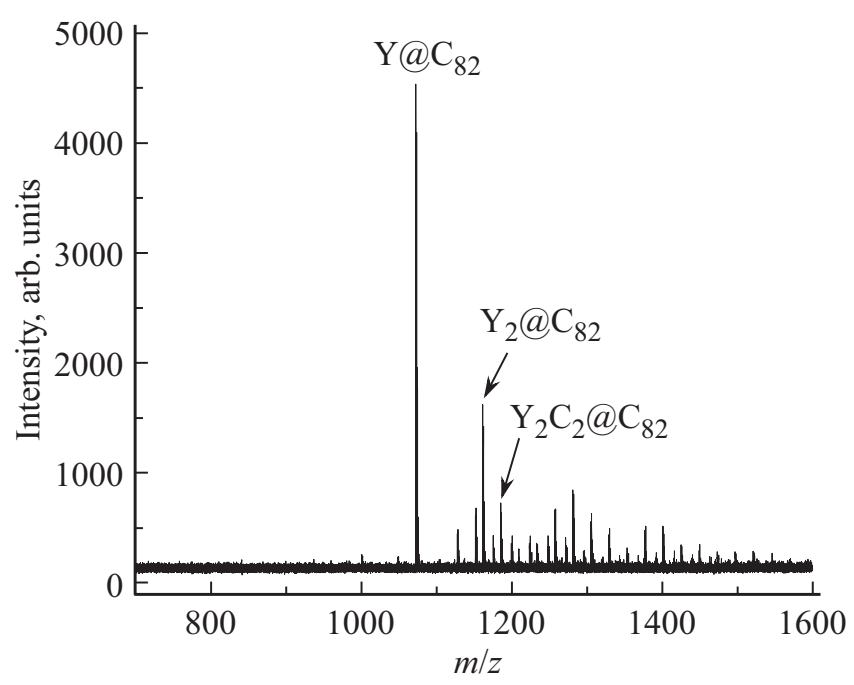

Рис. 1. Масс-спектр в положительных ионах хроматографической фракции. 
температуре $21^{\circ} \mathrm{C}$. Полученные данные позволили рассчитать действительную $Z^{\prime}(f)=|Z(f)| \cos \varphi(f)$ и мнимую $Z^{\prime \prime}(f)=|Z(f)| \sin \varphi(f)$ компоненты импеданса, определить эффективную емкость $C_{\mathrm{eff}}(f)=$ $=Z^{\prime \prime}(f) /\left(\omega Z^{\prime}(f) R_{\mathrm{eff}}(f)\right)$ и эффективное сопротивление пленки $R_{\mathrm{eff}}(f)=Z^{\prime}(f)\left(1+Z^{\prime \prime 2}(f) / Z^{\prime 2}(f)\right)$ [14]. Далее, с учетом проведенной калибровки измерительного датчика, были вычислены частотные зависимости действительной $\varepsilon^{\prime}$ и мнимой $\varepsilon^{\prime \prime}$ компонент диэлектрической проницаемости (ДП) [15] и проводимости $Y^{\prime}=Z^{\prime}(f) /|Z(f)|$, $Y^{\prime \prime}=Z^{\prime \prime}(f) /|Z(f)|[14]$, которые приведены на рис. $2, a, b$ соответственно.

Как видно на рис. 2, $a$ в пленке отчетливо наблюдается высокие значения как действительной $\varepsilon^{\prime}$, так и мнимой $\varepsilon^{\prime \prime}$ компонент ДП в области низких частот, что указывает на существование процессов движения и накопления электрических зарядов, в данном случае протонов [16]. Образец обладает заметной действительной компонентой проводимости $Y^{\prime}$, которая в области низких частот имеет величину $\sim 3 \cdot 10^{-6} \Omega^{-1}$, а с ростом частоты возрастает до значений $\sim 10^{-4} \Omega^{-1}$. Возрастание мнимой компоненты проводимости $Y^{\prime \prime}(f)$ на


Рис. 2. Зависимость от частоты: $a$ - действительной $\left(\varepsilon^{\prime}\right)$ и мнимой $\left(\varepsilon^{\prime \prime}\right)$ компонент ДП; $b-$ действительной $\left(Y^{\prime}\right)$ и мнимой $\left(Y^{\prime \prime}\right)$ компонент проводимости.

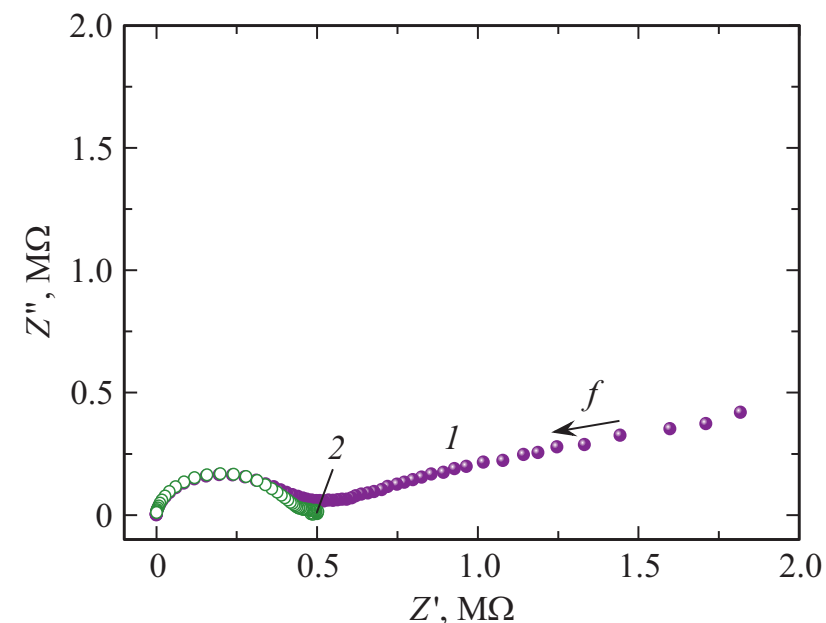

Рис. 3. Годограф сопротивлений пленки в диапазоне частот $0.1 \mathrm{~Hz}-3 \mathrm{MHz} .1$ - без постоянного смещения, 2 - с добавлением постоянного смещения $2 \mathrm{~V}$.

высоких частотах в основном определяется величиной эффективной емкости $Y^{\prime \prime}(f)=2 \pi f C_{\text {eff }}(f)$.

Частотно зависимое сопротивление образца, скорее всего, связано с прыжковым механизмом проводимости, что подтверждается возрастанием действительной компоненты проводимости $Y^{\prime}$ на высоких частотах [17]; действительная компонента проводимости мало меняется с частотой (до $1 \mathrm{MHz}$ ), а затем возрастает (рис. 2, $b$ ). Это характерно для многих неоднородных по структуре материалов, обладающих прыжковой или поляронной проводимостью.

Малое изменение $Y^{\prime \prime}$ с ростом частоты до $10^{3} \mathrm{~Hz}$ связано с перемещением носителей зарядов между электродами в объеме пленки. На низкой частоте носители заряда успевают перемещаться вслед за изменением поля, и $Y^{\prime \prime}$ принимает минимальное значение, а $\varepsilon^{\prime}$ максимальное. Минимальную частоту, начиная с которой $Y^{\prime \prime}$ начинает линейно расти с ростом частоты, обычно считают началом низкочастотной области, где носители заряда могут перемещаться между электродами.

Электрофизические процессы поляризации и переноса зарядов в исследуемом образце видны на годографе сопротивлений $[9,18]$, построенного как зависимость мнимой компоненты импеданса $Z^{\prime \prime}$ от действительной компоненты $Z^{\prime}$ (рис. 3). Каждой точке годографа соответствует определенная частота, а стрелка на рисунке указывает направление, в котором частота возрастает.

Годограф состоит из дуги окружности и так называемого луча. Дуга окружности соответствует собственной геометрической емкости измерительной ячейки. Точка перегиба между этими областями соответствует частоте, на которой $Y^{\prime \prime}$ начинает возрастать. Также эта точка соответствует максимальной протонной проводимости пленки [16]. Зная геометрические размеры пленки, мы определили ее удельную протонную проводимость $\sim 5 \cdot 10^{-3}(\Omega \cdot \mathrm{cm})^{-1}$. Существование поляризации носи- 




Рис. 4. Вольт-амперная характеристика пленки. Каждый цикл начинался с нуля. Стрелками показано направление изменения напряжения. $1-$ первый цикл, $2-$ второй цикл, $3-$ третий цикл.

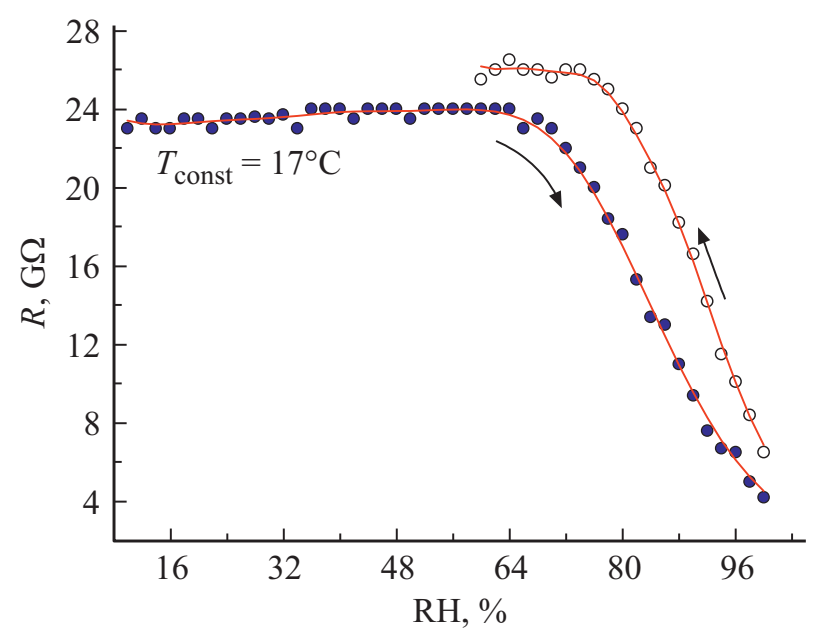

Рис. 5. Влияние относительной влажности на сопротивление пленки.

телей заряда на электродах можно доказать добавлением постоянного смещения к измерительному переменному сигналу. В результате (график 2 на рис. 3) можно наблюдать полную компенсацию потенциального барьера.

Гистерезис на вольт-амперной характеристике пленки (рис. 4) является следствием накопления носителей заряда вблизи электродов. Заряд сохраняется некоторое время и создает электрическое поле, противоположно направленное внешнему полю. С каждым новым циклом это приводит к уменьшению угла наклона ВАХ к оси абсцисс, т. е. сопротивление пленки увеличивается.

Сопротивление пленки на постоянном токе в зависимости от влажности воздуха при постоянном объеме и температуре показано на рис. 5. До значения влажности 64\% сопротивление почти не менялось. Дальнейший рост влажности приводит к резкому уменьшению сопро- тивления по линейному закону. Наблюдается некоторый гистерезис, возможно связанный с медленным проникновением воды в объем пленки.

В соответствии с вышесказанным, данный образец пленки следует рассматривать как пространственно неоднородную структуру, которая в переменном электрическом поле может сильно поляризоваться, что приводит к возникновению аномально больших внутренних емкостей и проводимостей.

Сегнетоэлектрические свойства пленки мы исследовали методом PUND (Positive Up Negative Down) [19]. Исследования показали, что наблюдается остаточная поляризация, значение которой $0.136 \mu \mathrm{C}$. С учетом толщины пленки величина $P_{r} \sim 0.75 \mu \mathrm{C} / \mathrm{cm}^{2}$.

Исследование импедансных характеристик пленки, полученной на основе гидроксилированных ЭМФ с $Y$, показало, что вещество обладает $\varepsilon^{\prime}$, достигающей величины $10^{4}$ и $\varepsilon^{\prime \prime} \sim 10^{5}$ на частотах вблизи $10 \mathrm{~Hz}$. Удельную проводимость исследуемой пленки можно оценить величиной $5 \cdot 10^{-3}(\Omega \cdot \mathrm{cm})^{-1}$. Измерения показали, что пленка на основе ЭМФ с $Y$ - сегнетоэлектрик с величиной остаточной поляризации $P_{r} \approx 0.75 \mu \mathrm{C} / \mathrm{cm}^{2}$. Исходя из полученных результатов, можно сделать вывод, что такие важные параметры изделий на основе гидроксилированных ЭМФ с $Y$ как величина ионной проводимости и сегнетоэлектрические свойства зависят от количества физически связанной воды в веществе, т.е. от способа получения изделия и от состояния окружающей среды, в которой изделие эксплуатируется.

\section{Список литературы}

[1] R.B. Ross, C.M. Cardona, D.M. Guldi, S.G. Sankaranarayanan, M.O. Reese, N. Kopidakis, J. Peet, B. Walker, G.C. Bazan, E. van Keuren, B.C. Holloway, M. Drees. Nature Mater. 8, 208 (2009).

[2] W. Harneit. Phys. Rev. A. 65, 3, 032322 (2002).

[3] S. Keshri, B.L. Tembe. J. Chem. Phys. 146, 074501 (2017).

[4] H.C. Dorn, P.P. Fatouros. Nanosci. Nanotechnol. Lett. 2, 2, 65 (2010).

[5] Z. Chen, R. Mao, Y. Liu. Current Drug Metabolism 13, 1035 (2012).

[6] M. Rudolf, S. Wolfrum, D.M. Guldi, L. Feng, T. Tsuchiya, T. Akasaka, L. Echegoyen. Chem. Eur. J. 18, 5136 (2012).

[7] M.E. Rincón, R.A. Guirado-López, J.G. Rodríguez-Zavala, M.C. Arenas-Arrocena. Solar Energy Mater. Solar Cells 87, $1-4,33$ (2005).

[8] А.Л. Шахмин, С.В. Мурашов, Н.В. Баранов, М.А. Ходорковский. ФТТ 40, 168 (1998).

[9] O. Gunnarsson. Rev. Mod. Phys. 69, 2, 575 (1997).

[10] G. Churilov, A. Popov, N. Vnukova, A. Dudnik, N. Samoylova, G. Glushenko. Fullerenes, Nanotubes Carbon Nanostruct. 24, 11, 675 (2016).

[11] G.N. Churilov, W. Kratschmer, I.V. Osipova, G.A. Glushenko, N.G. Vnukova, A.L. Kolonenko, A.I. Dudnik. Carbon 62, 389 (2013).

[12] K. Akiyama, T. Hamano, Y. Nakanishi, E. Takeuchi, S. Noda, Z. Wang, S. Kubuki, H. Shinohara. J. Am. Chem. Soc. 134, 9762 (2012). 
[13] L.Y. Chiang, R.B. Upasani, J.W. Swirczewski, S. Soled. J. Am. Chem. Soc. 115, 5453 (1993).

[14] Impedance Spectroscopy Theory, Experiment, And Applications / ed. E. Barsoukov, J.R. Macdonald. Hoboken. Published by John Wiley \& Sons, Inc. New Jersey (2005). 595 p.

[15] D.K. Pradhan, R.N.P. Choudhary, B.K. Samantaray. Int. J. Electrochem. Sci. 3, 597 (2008).

[16] K. Hinokuma, M. Ata. J. Electrochem. Soc. 150, 1. A112 (2003).

[17] G.F. Neumark. Phys. Rev. B 20, 4, 1519 (1979).

[18] H. Yang, C. Lu, Z. Liu, H. Jin, Y. Che, M.M. Olmstead, A.L. Balch. J. Am. Chem. Soc. 130, 17296 (2008).

[19] Ferroelectrics - Physical Effects / Ed. M. Lallart. Publisher: InTech, Chapter published. (2011). P. 77-100.

Редактор К.В. Емцев 